\title{
Alimentos Bromatología
}

SEGUNDA EDICIÓN
Carlos Alvarado-Ortíz Ureta Teresa Blanco Blasco

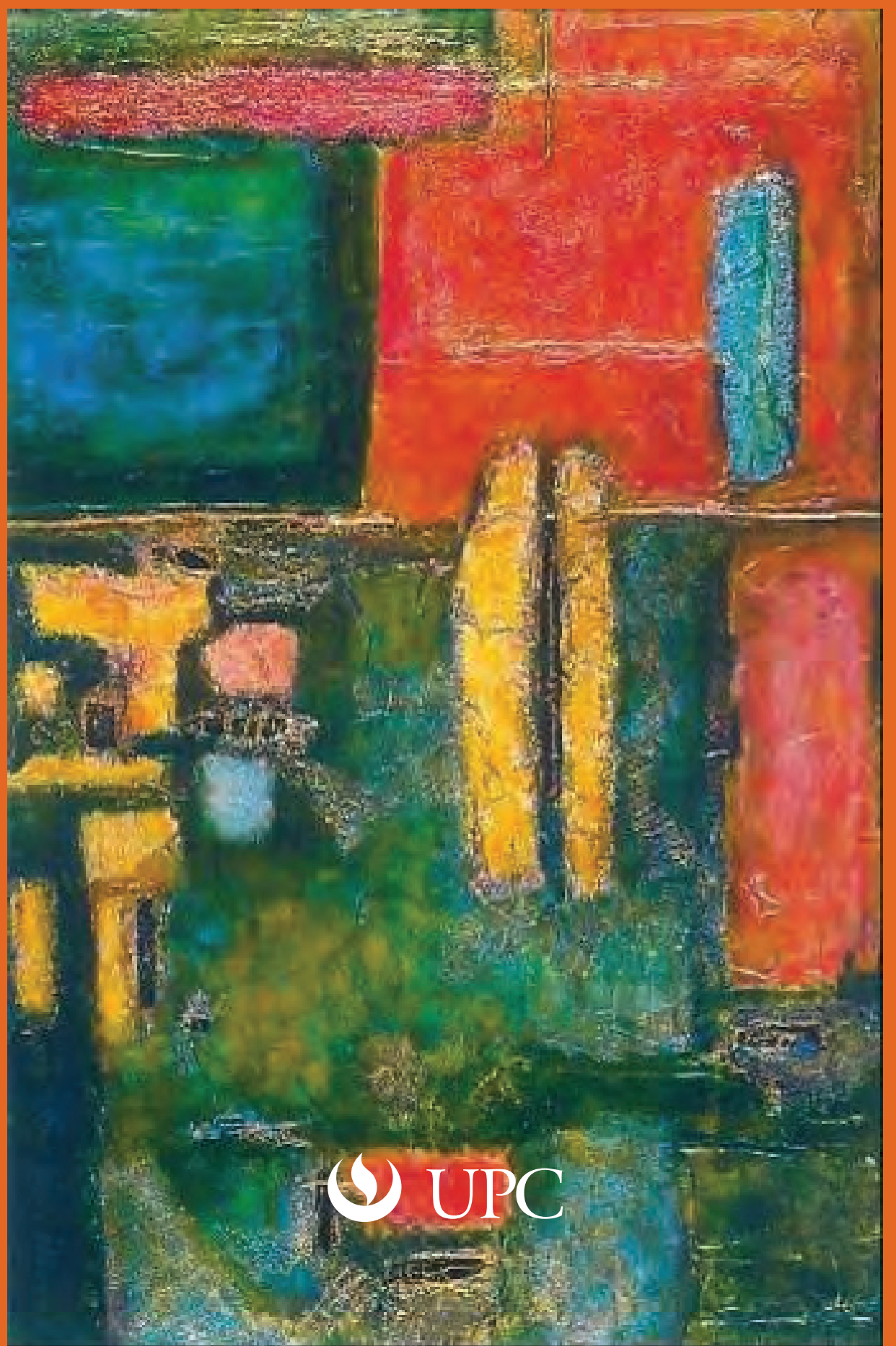





\section{Alimentos Bromatología}

Segunda Edición

Carlos Alvarado-Ortiz Ureta Teresa Blanco Blasco

Lima, abril de 2008

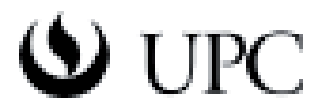


Autor: Carlos Alvarado-Ortiz Ureta y Teresa Blanco Blasco

(C) Universidad Peruana de Ciencias Aplicadas (UPC)

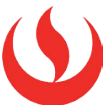

Segunda edición: abril de 2008

Cubierta: Nora Sidoine

Corrección de estilo: Jorge Coaguila

Diseño de cubierta: Giuliana Abucci

Diagramación: Giuliana Abucci, Ana Vilca

Imágenes: $\quad$ Copyright (C) 2008 Teresa Blanco y sus licenciantes.

Todos los derechos reservados.

(C) Universidad Peruana de Ciencias Aplicadas SAC

Av. Alonso de Molina 1611, Lima 33, Perú

Telef. 313-3333

http://www.upc.edu.pe

Digitalizado y Distribuido por YoPublico S.A.C.

\section{2 yopublico}

www.yopublico.net

Telf: 51-1-2219998

Dirección: Av. 2 de Mayo 534 Of. 304, Miraflores Lima-Perú

\section{Universidad Peruana de Ciencias Aplicadas (UPC) Centro de Información}

Alvarado-Ortiz Ureta, Carlos y Blanco Blasco, Teresa. Alimentos. Bromatología

Lima: Universidad Peruana de Ciencias Aplicadas (UPC), 2015

ISBN de la versión impresa: 978-603-4019-83-6

ISBN de la versión PDF: 978-612-4041-62-4

ISBN de la versión e-Pub: 978-612-4191-73-2

ALIMENTOS, COMPOSICIÓN DE LOS ALIMENTOS, HORTALIZAS, CEREALES, ACEITES COMESTIBLES, PRODUCTOS LÁCTEOS, CARNE, PRODUCTOS PESQUEROS

641.3 ALV

Todos los derechos reservados. Esta publicación no puede ser reproducida, ni en todo ni en parte, ni registrada en o transmitida por un sistema de recuperación de información, en ninguna forma ni por ningún medio, sea mecánico, fotoquímico, electrónico, magnético, electroóptico, por fotocopia o cualquier otro, sin el permiso previo, por escrito, de la editorial.

El contenido de este libro es responsabilidad de los autores y no refleja necesariamente la opinión delos editores. 
Horizonte interior Técnica mixta sobre lienzo $0,92 \times 0,61 \mathrm{~m}$ 2007

La Universidad Peruana de Ciencias Aplicadas (UPC) agradece a Nora Sidoine la cesión de su cuadro reproducido en la cubierta. 


\section{Contenido}

Presentación

Prólogo xi

Introducción xiii

CAPÍtulo 1 : Cronología de los alimentos en el mundo 1

Capítulo 2 : Alimentos del Perú 43

CAPÍtulo 3 : Alimentos 65

CAPÍtUlo 4 : Hortalizas 123

CAPÍtUlo 5 : Frutas 155

CAPÍtulo 6 : Hortalizas aromáticas y especies 195

CAPÍtulo 7 : Hortalizas de tierra 217

CAPÍtULO 8 : Cereales 233

CAPÍtulo 9 : Cultivos más consumidos por el poblador andino 253

CAPÍTULO 10: Leguminosas 267

CAPÍTULO 11: Aceites y grasas 283

CAPÍTULO 12: Azúcares y derivados 303

CAPÍTULO 13: Lácteos 329

CAPÍtUlo 14: Huevos 355

CAPÍtulo 15: Carnes 371

CAPÍtulo 16: Pescados y productos del mar 393

CAPÍTULO 17: Deterioro de los alimentos 427

CAPÍtulo 18: Flavor de los alimentos 449

CAPÍTULO 19: Biotecnología 465

Sobre los autores de las lecturas $\quad 483$

$\begin{array}{ll}\text { Publicaciones } & 487\end{array}$ 



\section{Presentación}

Consumir alimentos es una necesidad básica de todo ser vivo, es la única forma de obtener la energía y los elementos indispensables para el adecuado funcionamiento de nuestro organismo. Los alimentos constituyen una fuente natural de nutrientes $y$, por ello, desempeñan un papel decisivo en nuestro desarrollo.

Cada vez es más evidente la importancia de una adecuada elección de los alimentos que ingerimos por su estrecha relación con la nutrición y la salud. ¿Cómo y qué elegir entre la diversidad de opciones para alimentarnos bien? Gran parte de la solución consiste en conocer un poco más los alimentos que consumimos.

Es precisamente en este punto donde radica la importancia del presente libro Alimentos Bromatología. Una renovada obra que nos habla de manera ágil y didáctica sobre la naturaleza y características de los alimentos, sobre su composición química, su aporte de nutrientes, la forma de conservación de los mismos y también las condiciones que influyen en su deterioro, así como aquellas que nos ayudan a conservarlos. Es decir, nos introduce al universo de los alimentos para que podamos profundizar nuestros conocimientos sobre ellos, describiendo los diversos procesos enzimáticos y bioquímicos que ocurren al interior de los mismos, para que valoremos su inocuidad, para que sepamos combinarlos de acuerdo con su valor nutricional y seleccionarlos y consumirlos en el momento ideal.

La Fundación Ajinomoto para el Desarrollo de la Comunidad, manteniendo su compromiso "de difundir y poner al servicio de la comunidad en general importantes conocimientos y experiencias en las áreas de nutrición y alimentación", se honra en compartir esta segunda edición del libro Alimentos Bromatología, obra de la doctora Teresa Blanco Blasco y del doctor Carlos Alvarado-Ortiz Ureta, ambos reconocidos investigadores y académicos cuya pasión por el campo de la alimentación y la salud se refleja una vez más en esta valiosísima obra cuyo fin es también el de contribuir a una mejor salud y, por ende, a una mejor calidad de vida para todos. 
En el 2003, sentimos la misma emoción y orgullo de poner al servicio de la comunidad importantes conocimientos compartidos en la primera edición de este libro, el mismo que por su calidad académica tuvo una gran acogida. Motivados por la demanda del público en general, al poco tiempo del lanzamiento del primer número se programó una segunda edición, por lo que esta vez, con el concurso de la Universidad Peruana de Ciencias Aplicadas (UPC), presentamos esta innovada segunda edición de Alimentos Bromatología. Sin duda, una edición largamente esperada por todos aquellos involucrados en el maravilloso mundo de las ciencias de alimentos: profesionales y estudiantes de gastronomía, nutrición y ciencias de la salud, quienes, estamos seguros, encontrarán en este libro una valiosa herramienta de consulta y de referencia, además de disfrutar de una interesante obra de arte académica.

\section{Katsuaki Ogawa}

Presidente del Directorio y Gerente General

Ajinomoto del Perú S. A. 


\section{Prólogo}

Los autores de este libro, Teresa Blanco Blasco y su esposo, Carlos Alvarado-Ortiz Ureta, son estudiosos apasionados del tema de los alimentos y expertos reconocidos internacionalmente en este campo. En esta segunda edición del libro Alimentos Bromatología señalan que los alimentos son parte fundamental de la vida, sin embargo, los escogemos, los consumimos por hábito, porque son agradables, vistosos, fáciles de preparar y que pocas veces nos detenemos a recordar su valor nutritivo o a pensar en cómo mejorar este a través de mezclas apropiadas entre ellos.

Alimentos Bromatología, en cada uno de sus capítulos, nos facilita ese conocimiento, nos invita a ver cada alimento como un gran complejo de estructuras químicas: agua, proteínas, grasas, carbohidratos digeribles, fibra, nucleótidos, fotoquímicos, antioxidantes, aldehídos, cetonas, carboxilos.

El libro nos familiariza con los cambios bioquímicos que ocurren en la maduración de los alimentos de origen vegetal, convirtiéndose en verdaderos indicadores al momento de elegirlos. En el grupo de alimentos animales nos explica los cambios bioquímicos en el músculo, en la grasa, en el tejido conectivo, antes de la captura o sacrificio del animal, como también en el almacenamiento y preparación de cada uno de ellos.

La diferencia de este libro en relación con su primera versión la observamos claramente en el haber puntualizado la bibliografía, haber dado mayor cabida a alimentos de origen peruano, cultivados o criados en el Perú, ubicándolos en su lugar de origen.

Otra innovación en esta segunda edición es que en cada capítulo se incluye una lectura interesante, escrita por profesionales muy conocedores del tema, lo que despierta un interés muy especial en profundizar en el estudio del capítulo.

El deseo de los autores, con el que coincido plenamente, es que nutricionistas, gastrónomos, profesionales de los alimentos y de las ciencias de la salud encuentren una mejor guía para la selección de los alimentos y 
que ello se traduzca en un justo y adecuado consumo de alimentos por la población, con criterios suficientes de discernimiento frente a información no muy clara, poco precisa y a veces poco veraz.

Estoy segura de que el libro será una herramienta muy útil para estudiantes y profesionales y que contribuirá a valorar cada vez mejor estos nobles frutos de la naturaleza, los alimentos.

Graciela Risco de Domínguez

Vicerrectora Académica de la

Universidad Peruana de Ciencias Aplicadas (UPC) 


\section{Introducción}

Al escribir Alimentos Bromatología no pensamos que tendría una acogida tan especial, la que hoy nos obliga a ofrecer esta segunda edición —como se estila-, corregida y aumentada, que llega a ustedes en impecable presentación, gracias a la suma de voluntades de la Fundación Ajinomoto para el Desarrollo de la Comunidad y el Fondo Editorial de la Universidad Peruana de Ciencias Aplicadas (UPC). Para ellos, nuestro cálido agradecimiento.

Deseamos que —como sucedió en la primera edición- este volumen llegue a muchas personas, a todas aquellas para quienes en los alimentos siempre ven algo bueno, que nos da vida, pero que — a la vez- son frágiles, que deben ser escogidos, cuidados, valorados. Sin ellos, no se concibe el bienestar, la fuerza para trabajar, estudiar, ser felices, hacer deporte.

Hemos mejorado todos los capítulos, todos los temas se han escrito privilegiando a los alimentos que se consumen en el Perú, resaltando aquellos que —desde este país y esta promisoria América del Sur- ocupan hoy un lugar especial en la alimentación del mundo. De manera muy sencilla, nos ocupamos sobre el origen, características propias del alimento, color, sabor, olor, textura, composición química, tiempo de vida, enzimas y cambios que ellas originan, cocción, deterioro, formas de consumo, conservación y procesamiento.

Vivir tan intensamente la docencia, contar con libros que —como siempre decimos - valen oro, adquiridos en cada viaje, adquiridos vía internet, hijos, amigos que viajan, más el enseñar en universidades con centros de información tan completos, nos permite —una vez más - cruzar información, seleccionar lo más valioso de ella, volcando en cada línea lo que consideramos de utilidad en el campo de los alimentos.

La grata experiencia de insertar la sección Lecturas Interesantes en nuestro libro Aditivos alimentarios nos motiva a repetirla aquí, solicitando esta vez textos a Ivette Ludeña de Aliaga, Adriana Carulla, Víctor Manuel Castro, Martha Flórez, Vivian Geller, Emma Guerrero, Hernani Larrea, Alejandra Longa, Margarita López, José Llamosas, Ana María Muñoz, Hirka 
Roca Rey, Mónica Saavedra, Karin Servan, Carlos Silvera, Rodolfo Tafur, Andrés Velarde, María Elena Villanueva y Saby Zegarra, colegas, ex alumnos, empresarios, comunicadores. A todos ellos, muchas gracias también.

Los autores 
Capítulo 1
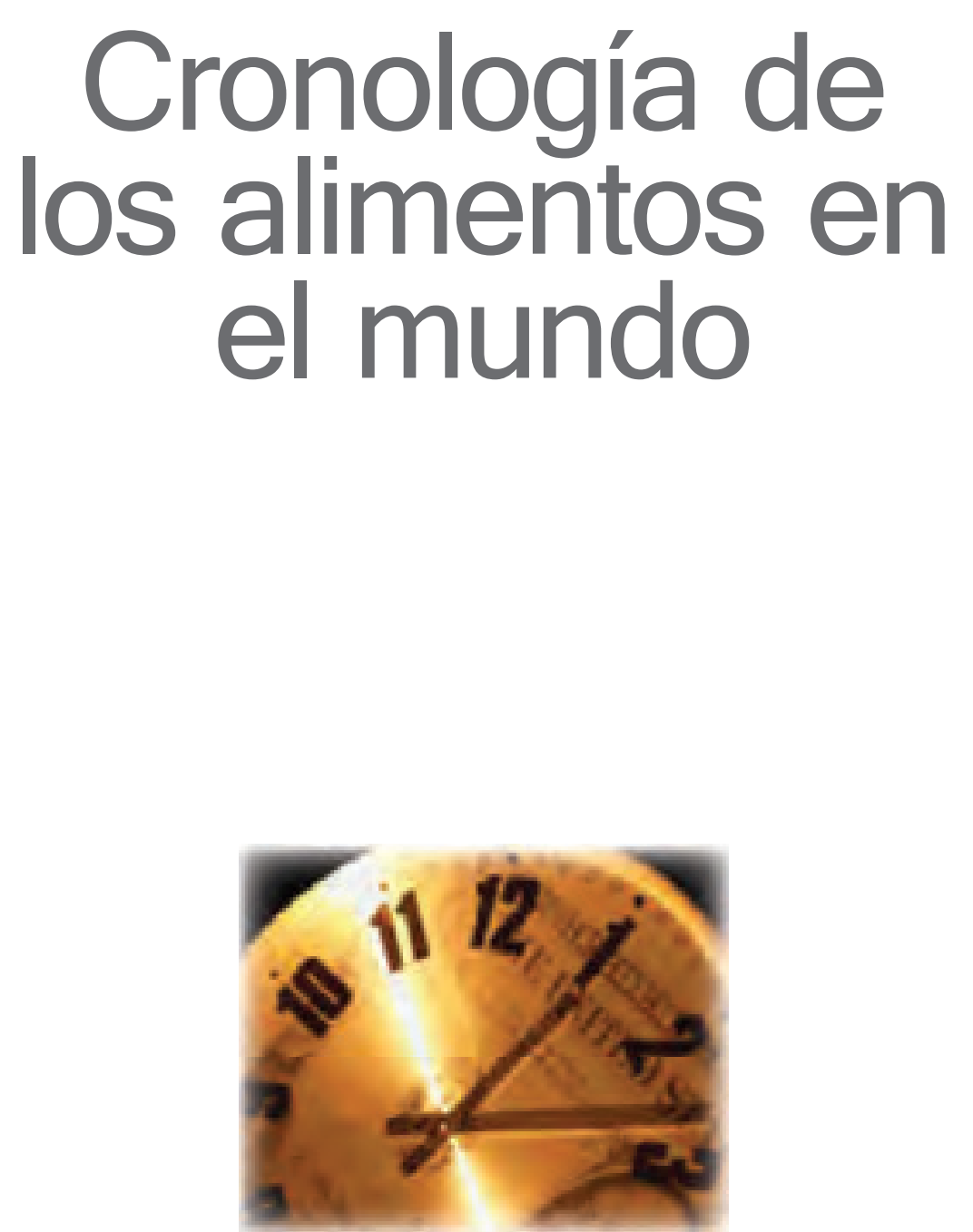


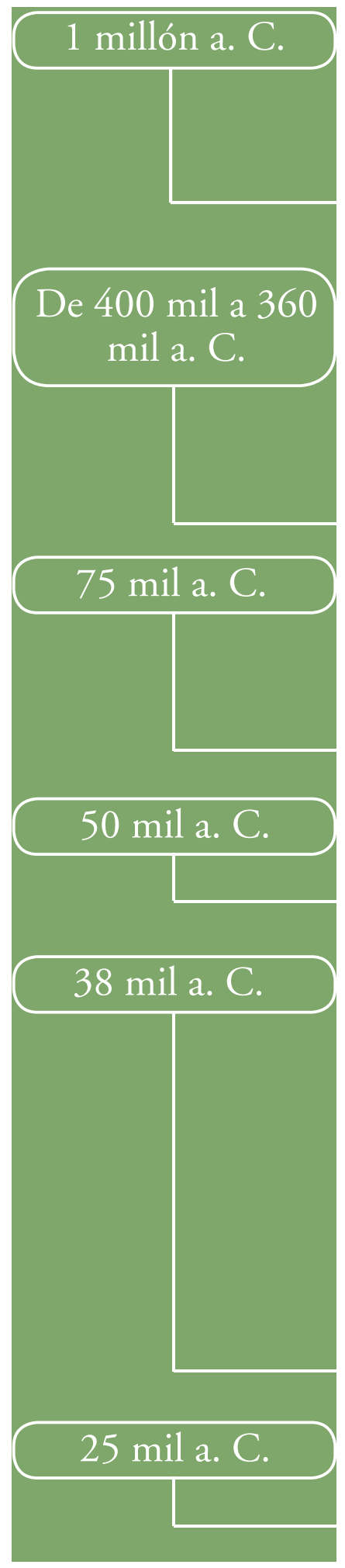

El Australopithecus se extingue y aparece el Homo erectus, primer esbozo de hombre, omnívoro, depredador que compite con las hienas y leopardos. Consume animales, raíces, nueces, hormigas y restos de médula ósea.

El Homo erectus del Pleistoceno Medio, llamado Pithecantropus pekinensis u Hombre de Pekín, comienza el uso del fuego para cocinar los venados que cazaba, aunque su utilización no era muy frecuente.

El hombre de Neandertal caza mamíferos tan grandes como elefantes, mamuts, tigres dientes de sable y otras criaturas que luego se extinguieron. La caza era su principal misión.

Los dátiles florecen en África y Asia, convirtiéndose en fuente alimenticia importante.

El Homo sapiens controla el fuego, cocina, prepara armas de hueso y cuerno, así como anzuelos para pescar. Los cazadores proveen a las primeras tribus de bisontes y tigres muertos, mientras que otros miembros pescan, recolectan miel de abeja, frutas y nueces, tal como se aprecia en las cavernas de Aurignac, en Francia. Todo este incremento en sus habilidades para obtener alimentos llevará a un aumento en la población.

El Homo sapiens emplea piedras precalentadas para cocinar alimentos cubiertos con hojas. 


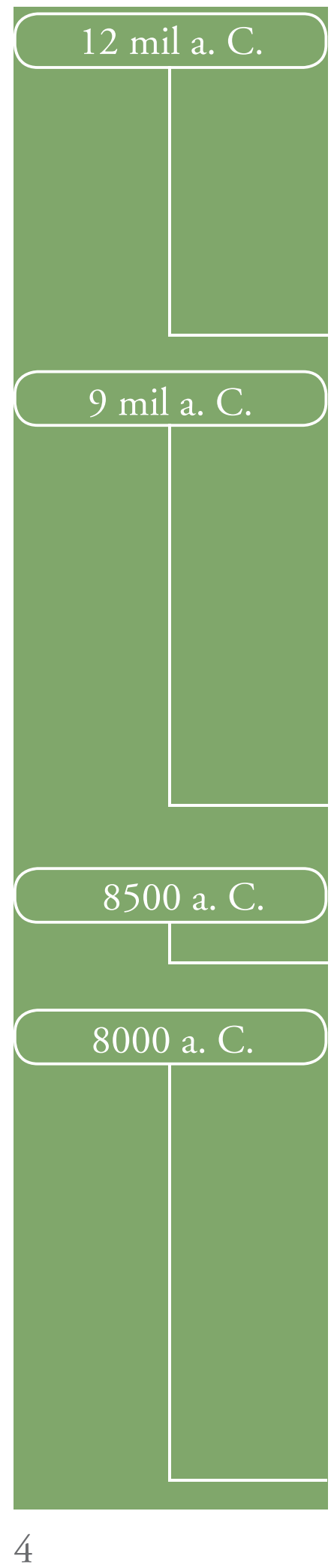

La tribu de Halfan en el bajo Nilo usaba piedras para producir harina de las semillas de cereales. En Nubia, en el alto Nilo, utilizaba una forma de cuchillo para cosechar los cereales que han comenzado a florecer.

En China la gente vivía de la caza, la pesca y la búsqueda de mariscos, los cuales son secados, ahumados y así queda conservados.

Aunque ya aparecen los arcos y las flechas, las lanzas continúan siendo las armas de caza más populares. A este periodo algunos modernos observadores llaman la Edad de Oro de la Nutrición, debido a la armonía entre gusto, aporte calórico, proteico y de micronutrientes con el sistema cardiovascular. Se come carne, abundantes vegetales, frutas, nueces, bayas, algo de pescado y mariscos. Solo se obtiene $20 \%$ de calorías de las grasas y no se padece enfermedad cardiovascular.

La leche de cabra empieza a utilizarse como fuente alimenticia en el Oriente Próximo.

La agricultura se inicia al final del Pleistoceno en el Oriente Próximo. Las mujeres usan varas de madera para plantar y cultivar semillas en pequeños espacios de tierra despejada. Cuando se aprecia que las semillas producen cosechas de granos y que 25 acres son suficientes para alimentar una familia dedicada al cultivo, a diferencia de los cientos y miles de acres necesarios para cazar y recolectar, mucha gente se vuelve sedentaria, lo que origina las comunidades. La población alcanza cinco millones de habitantes. 


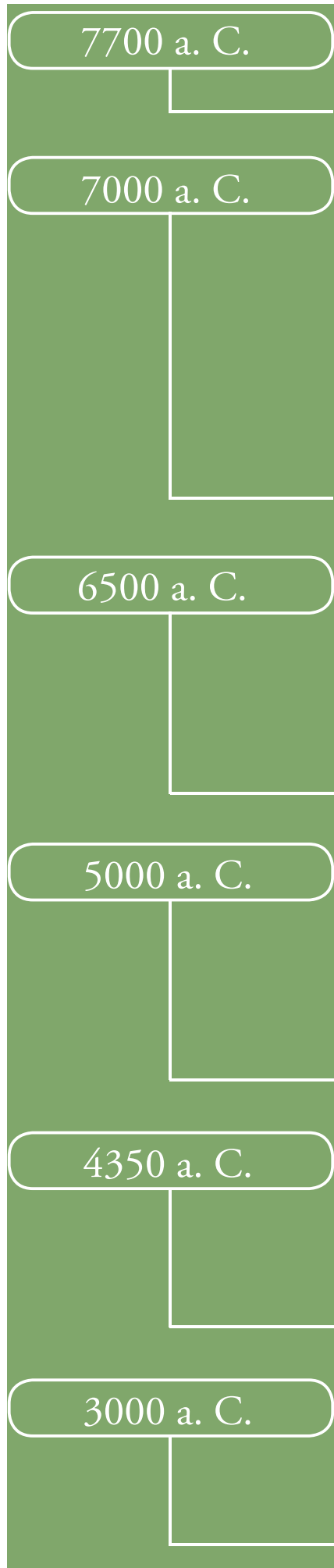

La leche de oveja es fuente de alimentación, así como la de cabra y la de mujer.

Los glaciares retroceden, permitiendo al hombre explorar nuevos lugares.

Los griegos se aventuran a pescar mar afuera, en lugar de hacerlo en la orilla. Cebada, mijo y algunas legumbres, como las lentejas, son cultivadas en Tesalia, donde los griegos también han domesticado perros y cerdos.

Los sumerios inventan la rueda, lo que cambia el transporte de alimentos y los lleva a los mercados.

Los bisontes, antecesores de los toros y vacas actuales, se convierten en fuente de carne, leche y cuero.

El ganado vacuno es común en los valles del Tigris y del Éufrates, que mantienen además canales de irrigación.

Se inicia el cultivo del arroz en el delta del río Yangzi, China.

Se domestican los caballos, que permiten transportar alimentos.

La población del mundo alcanza 80 millones de habitantes.

La agricultura es universal en toda China.

En los Andes se cultivan las primeras papas.

La población del mundo llega a 100 millones. 


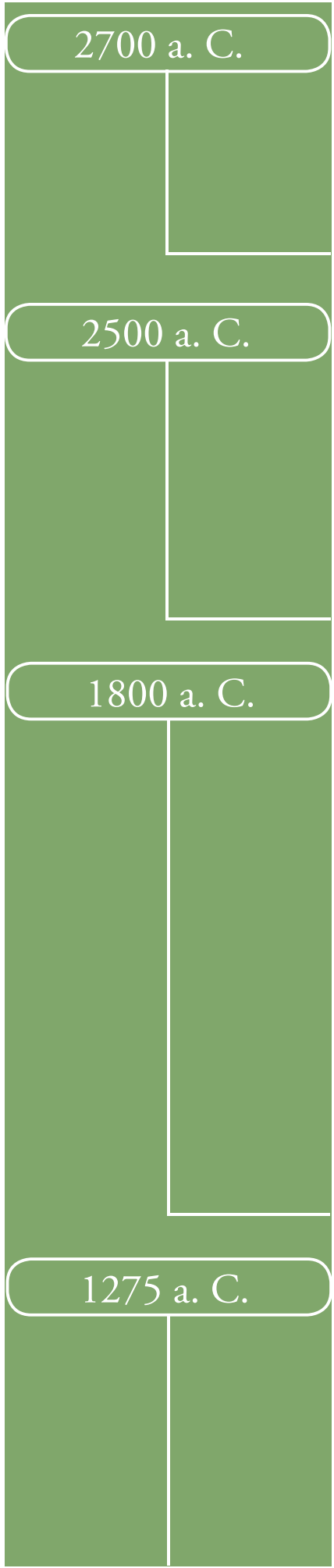

El emperador chino Shen Nung ordena a sus secretarios clasificar las plantas en términos de valor nutricional y medicinal.

Los egipcios conservan el pescado por secado al sol.

Llega la Era del Hierro. Se construyen varas de metal, que permiten cultivar con mayor profundidad en la tierra. El maíz es domesticado en Centroamérica. Lo mismo sucede con la papa y el camote en Sudamérica.

Árboles de olivo crecen en Creta y se produce el aceite de olivo.

Las proscripciones contra comer puerco en el Oriente Próximo quizá se debían a que sus habitantes eran rutinariamente pastores de ovejas y el cerdo era crianza de grupos enemigos.

Los babilonios emplean molinos de viento para irrigaciones.

Europeos del Este cultivan centeno, que pronto será el mayor grano para preparar pan.

Los egipcios inventan el pan fermentado (levantado), que duplica su tamaño por fermentación. Los ricos consumen pan de harina de trigo; los menos ricos, de cebada y los pobres, de sorgo.

Una migración de israelitas se produce de Egipto a Israel dirigida por el profeta Moisés y su hermano Aarón. En el camino se alimentan de maná, posiblemente una sustancia producida por el tamarindo, cuando su corteza es picada por algunos insectos o, tal vez, una forma de hongo. Los aristócratas egip- 


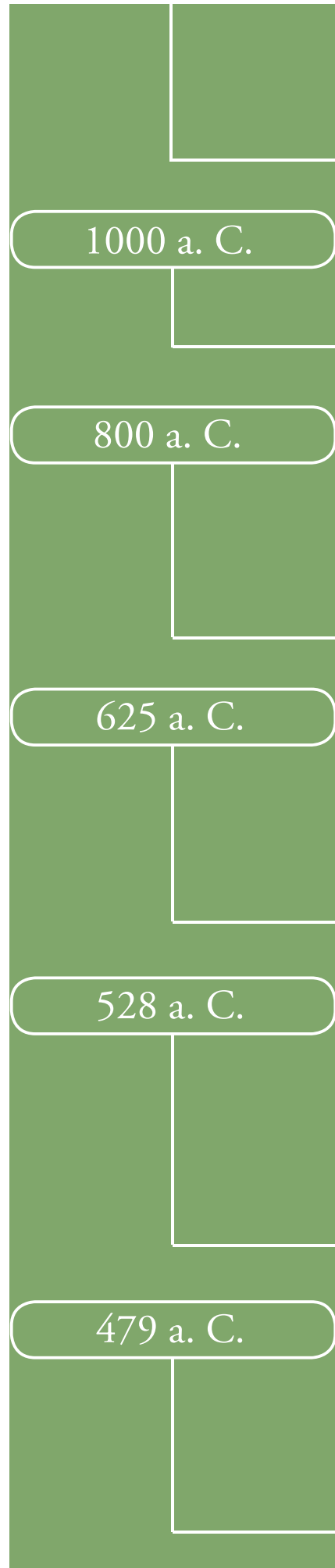

cios comían pan, tomaban vino y cerveza, comían en mesas y usaban sillas.

Los chinos bebían bebidas alcohólicas preparadas de mijo, frutas y bayas diferentes.

Los chinos cortan hielo y lo almacenan para preservar sus alimentos. La soya es introducida en China por pobladores del sur de Asia.

El ministro de Agricultura china dicta clases de rotación de cultivos, preparación de drenajes, renta de material de cultivo, formas de almacenar granos.

Leyes contra la matanza de animales son dictadas en la India.

Se introduce la moneda en Grecia. En cada lado hay una espiga de trigo o de cebada, para demostrar al pueblo que la Era del Trueque ha acabado.

El ganado vacuno de la India se extiende por el Mediterráneo.

El príncipe Siddhartha Gautama renuncia al lujo. Lleva una vida ascética y frugal para encontrar la iluminación. Será llamado el Buda Iluminado. Una parte esencial de su religión es el vegetarianismo, aunque luego lo abandonó. Murió a los 84 años después de haber comido abundante puerco.

El filósofo Confucio fallece a los 72 años. Deja sus escritos en el I Ching y en más de 300 canciones tradicionales, las que mencionan más de 44 alimentos distintos (el Antiguo Testamento solo menciona 29) y hacen cientos de referencias a los alimentos. 


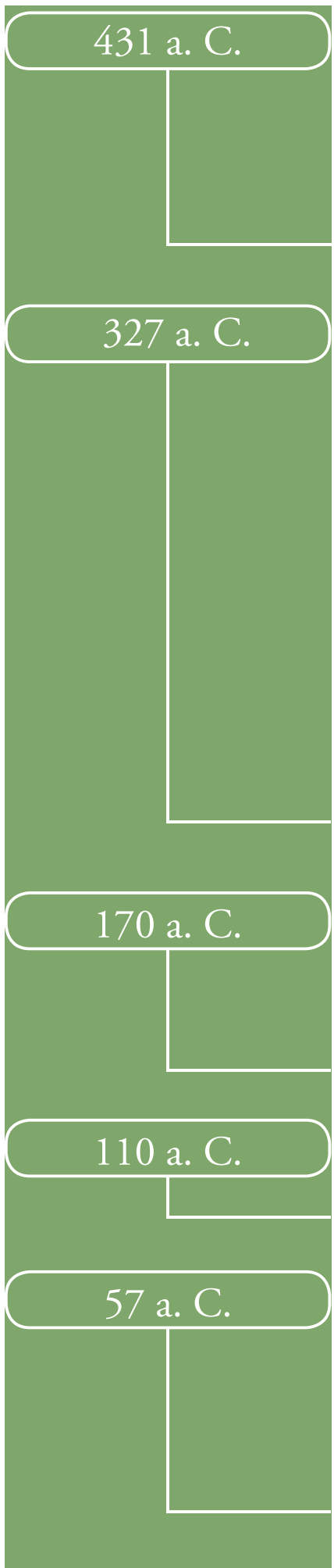

La pimienta es común en Grecia, aunque solo como medicina. No se usa aún como sazonador. El rey de Esparta recibe como obsequio una masa de grasa de ganso para preparar lo que se llamará después paté de foie gras.

Alejandro el Grande encuentra plátanos en un valle de la India. La primera referencia al azúcar de mesa aparece en escritos de este conquistador sobre indios que preparaban miel sin tener abejas. Aunque el azúcar había sido utilizado hace muchos años en China, el término azúcar proviene del árabe sukhar y este del sánscrito sarkara.

Roma obtiene su primera agua pura, cuando construye el primer acueducto a la ciudad.

Los chinos fermentan la soya y preparan una salsa, hoy sillao.

Aparecen en Roma las primeras cocinas profesionales, bajo la forma de panaderías comerciales, aunque la mayoría de las casas romanas preparan su harina y hornean su pan.

Cerca de Nápoles, los romanos - particularmente Sergius Orata- hacen fortuna cultivando ostras.

El poeta romano Tito Lucrecia Caro dice: "Lo que es alimento para un hombre puede ser veneno para otro".

Julio César invade Gran Bretaña, encuentra a los bretones preparando quesos y aprende de ellos. 


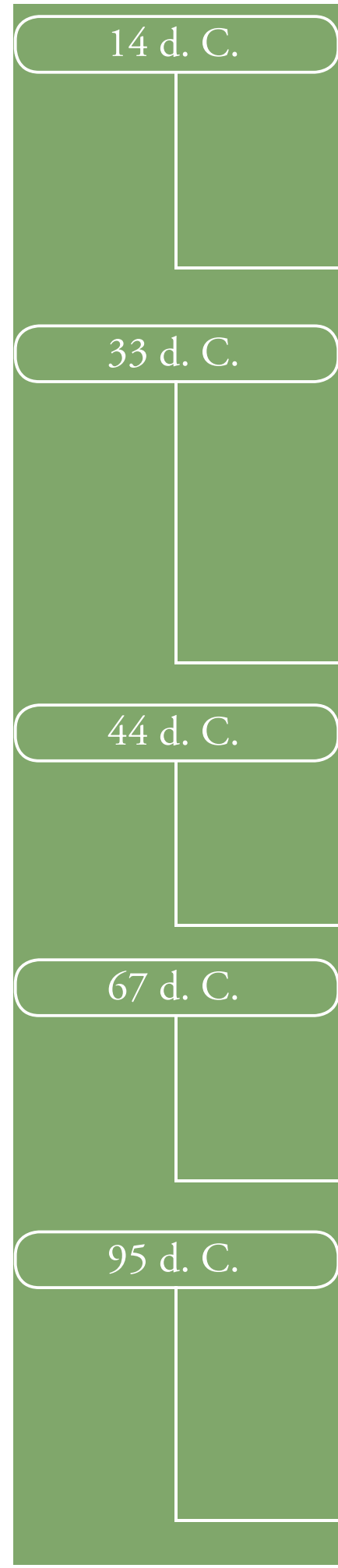

Año de la culinaria. Aparece el primer libro de cocina, el cual está firmado por Marcus Gavius Apicius, quien desarrolla recetas con brócoli. Además, prepara un ovemel con huevos y miel, que es el posible origen del omelet, plato predilecto del hijo de Tiberio.

El judío Jesús de Nazaret viaja a Jerusalén para recibir la Pascua con sus 12 apóstoles. Luego de la última cena, es traicionado, blasfemado y crucificado. De ahí sale la superstición de que 13 sujetos en una comida trae mala suerte. Sin embargo, esa creencia proviene de la mitología escandinava, que antecede al cristianismo, donde el dios Loki se introduce a un banquete en el Valhalla y otro dios es muerto.

En Roma se hacen populares los vomitorios, donde esclavos estimulan la garganta de los comensales para provocar el vómito y permitirles volver a comer. Los romanos viven de pan, aceite de oliva, vino, pescado y muy poca carne.

Roma se interesa por los depósitos de sal en el Mar Muerto, pues la necesita en cantidad para queso, pan, vino y cerveza. El pago de los soldados es llamado salarium o moneda de sal. De ahí proviene el término salario.

Al menos diez acueductos suministran agua a Roma, aproximadamente 250 millones de galones por día (50 galones por persona). Pan y circo mantienen a la población de Roma pacífica a pesar de la pobreza. Las panaderías producen docenas de diferentes tipos de pan y el Estado los distribuye a los pobres gratuitamente. 


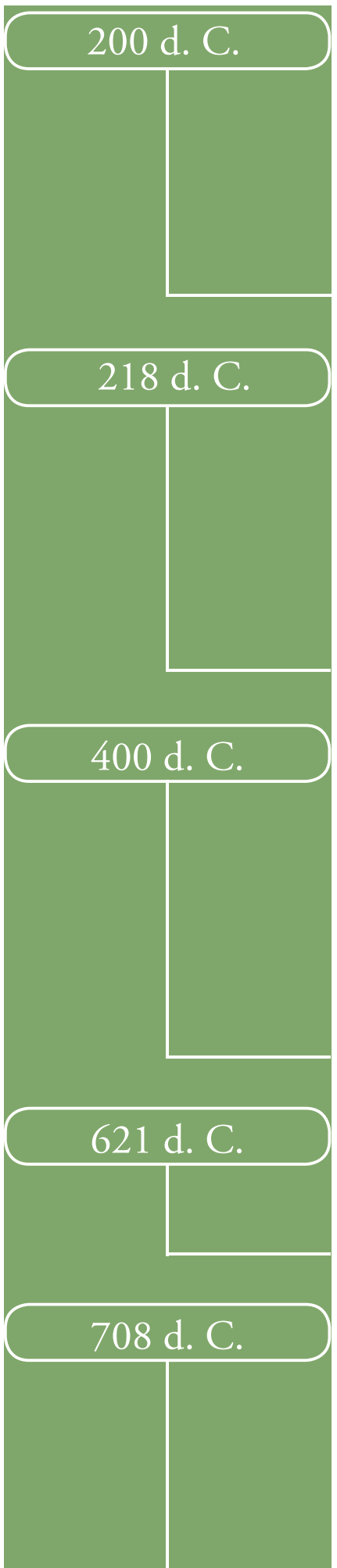

La comida común del romano consta de un desayuno con puré de frejol y galletas en miel o leche. El almuerzo se consume de pie en un lugar público y consiste en fruta, carne dulce, queso y vino. La cena consiste en carne, pescado, brócoli, cereales y cebollas fritas en aceite de oliva con vinagre.

El emperador romano Vario Avito Basiano, quien se llamaba a sí mismo Heliogábalo, mata en una fiesta 600 ostras para preparar un pastel.

Se inicia en China el uso del wok, sartén curva para calentar la mayoría de los alimentos. Se menciona por primera vez el té como sustituto del vino luego de una comida.

Los vándalos cruzan el Rin e invaden Europa. Traen la costumbre de consumir la mantequilla, que comienza a reemplazar al aceite de oliva. Traen también el centeno, la avena y el lúpulo.

La carretilla se inventa en China, la cual promueve la agricultura y la industria.

En Europa del Este se inventa la herradura.

Una misión enviada por el emperador Tai Zong estudia las técnicas de procesamiento de azúcar en la India.

El té gana popularidad en China, por ser más seguro y menos contaminado que el agua.

Se planta caña de azúcar en Egipto.

Los árabes invaden la península Ibérica e introducen en Europa el arroz, el azafrán y el azúcar de caña. 


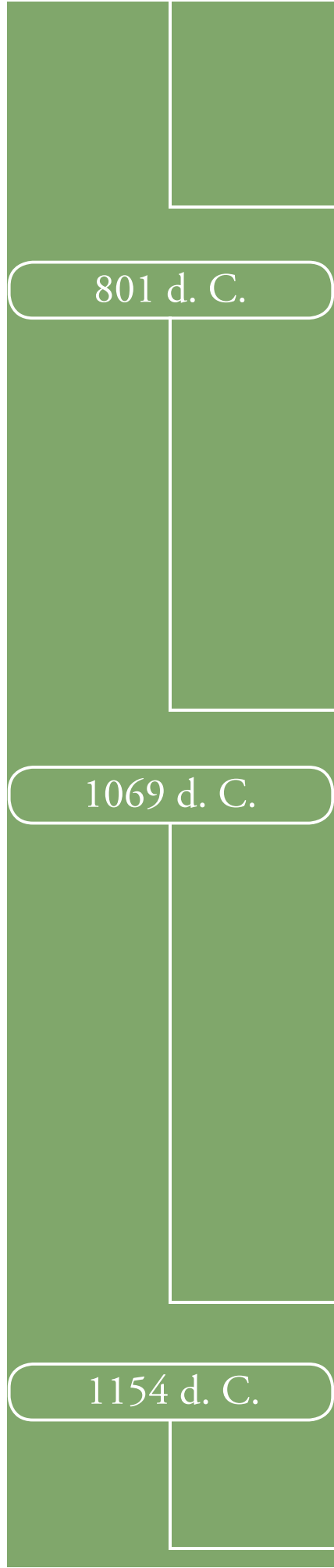

La costumbre china de comer con palitos se extiende a Japón.

Los sacerdotes chinos budistas introducen el azúcar a Japón, pero solo para enmascarar el mal sabor de las medicinas.

Los aristócratas chinos utilizan porcelana translúcida para comer. Esto solo se usará en Europa 900 años después.

El té es introducido a Japón como medicina. Los sarracenos invaden Sicilia, traen las espinacas de Persia.

El árabe Kaidi, pastor de cabras, descubre el café al sur de Etiopía. Observó que sus cabras se ponían eufóricas cuando consumían las bayas de cierto arbusto tropical que se había incendiado.

Guillermo el Conquistador gana la batalla de Hastings y se apodera de Inglaterra. Los vocablos franceses boeuf, mouton, porc y poularde son la base de los vocablos ingleses beef, mutton, pork y poultry, que en español son res, carnero, cerdo y ave.

El queso roquefort es descubierto en Francia. Se dice que Carlomagno lo comió con los monjes de Saint Gall, donde acostumbró ingerirlo con hongos verdes incluidos.

El tenedor de dos puntas es introducido en Venecia por una princesa griega que se casó con Doménico Selvo, dux de aquella república.

La industria vitivinícola de Inglaterra disminuye conforme aumenta y se abarata la francesa. Los granjeros ingleses introducen la crianza de conejos para la alimentación. 


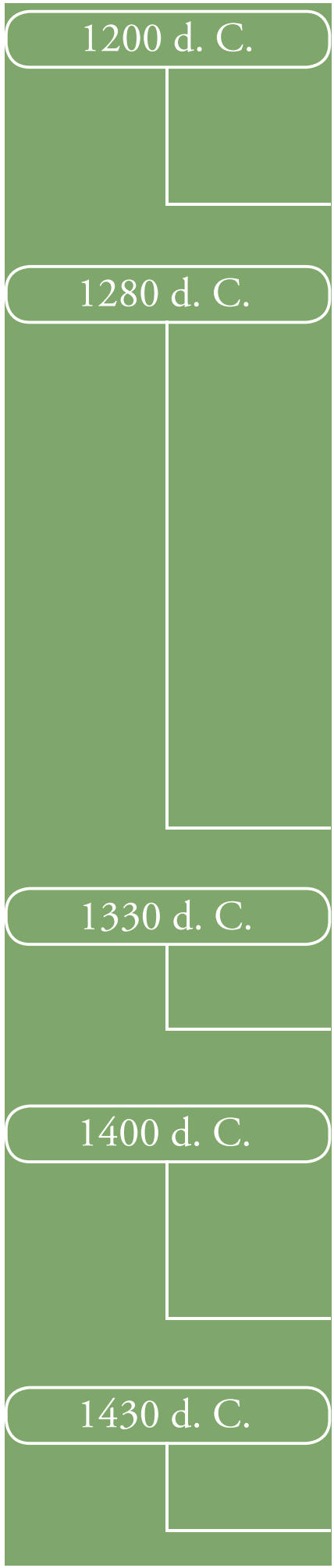

El queso de soya es introducido en Japón procedente de China, donde había sido consumido durante más de dos mil años como sustituto de la carne. Se introduce también el sillao.

En China del centro y del sur se consume 70\% de arroz y $30 \%$ de trigo y mijo, mientras que los del norte consumen harina de trigo y mijo bajo la forma de tallarines cocidos al vapor u horneados.

Los italianos inventan los macarrones, vocablo que derivaría del griego makar, que significa 'bendito', denotando un alimento con carácter religioso. Marco Polo lleva a Italia la lasaña, nombre dado por él a los tallarines chinos.

El primer brandy es destilado en la escuela médica de Montpellier por el profesor de medicina Arnaldus de Villa Nova.

En Principios de una dieta correcta, el dietista imperial Hoshoi muestra que muchas enfermedades se podían curar solo con dieta.

Se instalan tiendas italianas que producen pastas sobre bases comerciales. Mediante una harina de trigo duro se preparó una sémola, que servía para las pastas. Estos establecimientos empleaban vigilantes para proteger sus valiosos productos.

El vino español de Valdespino, en Jerez de la Frontera, comienza a producirse. Ganará en el futuro gran prestigio, junto a su manzanilla y amontillado. 


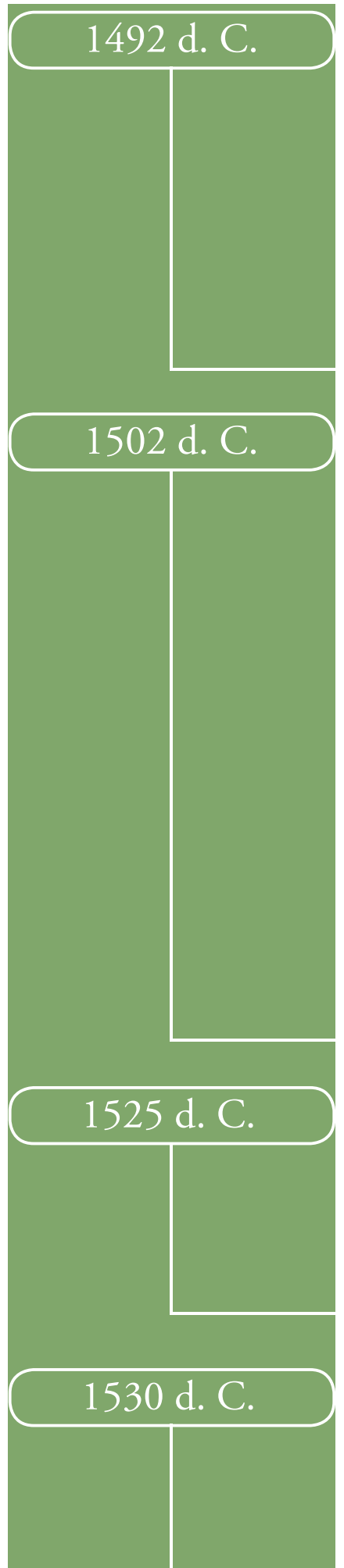

Cristóbal Colón y sus navegantes descubrirían en América un gran número de alimentos desconocidos para el resto del mundo, como carne de tortuga, camote, ají. Dos de sus miembros regresan de Cuba con una suerte de granos que llaman maíz. En un viaje a la isla de Guadalupe, Colón encuentra piñas. Algunas de estas frutas fueron llevadas a España, para el rey Fernando.

Colón recibe de los nativos una bebida llamada por ellos xocoatl, hecha con granos que — según la mitología- habían crecido en el jardín de los dioses. Quetzalcoatl vino a la tierra a enseñar a cultivar diversas plantas, como el cacao. Mezclado con miel $y$ vainilla, es servido fresco.

Girasoles de América son introducidos a Europa por España y en muchos países resultan importante fuente de aceite.

El religioso español fray Tomás de Berlanga introduce, en Santo Domingo y La Española, trigo, avena y plátano.

Llegan los primeros esclavos a Santo Domingo para labores en haciendas azucareras.

Pavos de América son introducidos en España, donde se les llama pavos reales. Cuando llegan a Inglaterra se confunden con las gallinas de Guinea, que habían transportado mercaderes turcos. Esta sería la razón de la palabra turkey.

La papa es descubierta en los Andes peruanos por el conquistador Gonzalo Jiménez de Quesada. Después de la papa, el tubérculo más utilizado en el antiguo Perú era la oca. Además, el inca comía 
Para poder revisar todo el contenido de esta edición, visite nuestra tienda virtual.

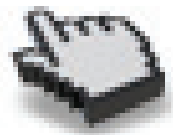

\section{Alimentos Bromatología}

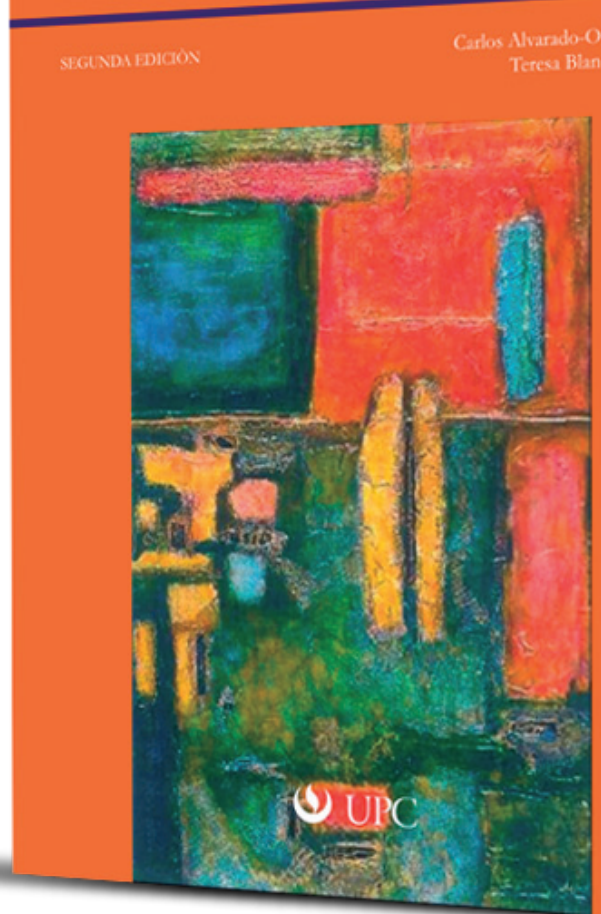

